\title{
DEGRADAÇÃO DO AZOCORANTE PONCEAU 4R EM SOLUÇÃO AQUOSA UTILIZANDO FOTO-OXIDAÇÃO CATALÍTICA
}

\author{
C. BENINCÁ ${ }^{1}$ e M. BAMPI ${ }^{2}$ \\ ${ }^{1}$ Universidade Federal do Rio Grande, Escola de Química e Alimentos \\ ${ }^{2}$ Universidade Federal de Santa Catarina, Departamento de Engenharia Química e Engenharia de \\ Alimentos \\ E-mail para contato: cristina.beninca@bol.com.br
}

\begin{abstract}
RESUMO - Neste trabalho foi realizado o estudo da degradação do azocorante vermelho Ponceau 4R, presente em uma solução sintética, utilizando foto-oxidação catalítica. Os experimentos foram realizados em um reator de vidro encamisado com volume de $250 \mathrm{~mL}$ por um tempo reacional de 120 minutos. A fonte de radiação UV foi uma lâmpada de vapor de mercúrio de $125 \mathrm{~W}$, inserida na solução por meio de um bulbo de quartzo. A solução de efluente sintético foi preparada com água destilada e corante na concentração de $60 \mathrm{mg} \mathrm{L}^{-1}$, e pH 4,0. Foi utilizado o semicondutor $\mathrm{TiO}_{2}(\mathrm{P} 25$ - 75\% anatase/25\% rutilo) como agente catalítico. Utilizando a concentração de $0,25 \mathrm{~g} \mathrm{~L}^{-1}$ de $\mathrm{TiO}_{2}$ no sistema reacional, obteve-se um percentual de remoção de cor de 99,40\%, no tempo de tratamento de 40 minutos. O decréscimo de Carbono Orgânico Total foi de 98,04\% aos 120 minutos de tratamento. Concluiu-se que o processo de foto-catalítico foi eficiente na degradação e mineralização do corante no tempo de tratamento de 120 minutos.
\end{abstract}

\section{INTRODUÇÃO}

Os resíduos gerados nas indústrias de alimentos apresentam algumas características que são comuns e devem ser consideradas como aspectos significativos para adequar o tipo de tratamento que deve ser utilizado para a remoção dos poluentes. Algumas destas características são: grande quantidade de matéria orgânica presente, como proteínas, carboidratos e lipídios; grande quantidade de sólidos suspensos; alta demanda química e bioquímica de oxigênio; alta concentração de nitrogênio; alto conteúdo de óleo e gordura suspensos e além de altas variações de $\mathrm{pH}$. Além disso, como caráter agravante de toda esta carga poluidora ainda tem a problemática de que as indústrias processadoras de alimentos apresentam alto consumo de água e geram alto volume de efluente por tonelada produzida quando comparada com outros setores industriais (Ramjeawon et al., 2004). Em virtude dos aportes de matéria orgânica, oriunda de efluentes de indústrias de alimentos ocorre a chamada eutrofização que é a proliferação de microvegetais oportunistas que podem liberar toxinas no corpo hídrico, causada pela baixa capacidade de autodepuração da carga orgânica pelo corpo receptor (Baumgarten, 2010). 


\section{9 a 22 de outubro de 2014 \\ Florianópolis/SC}

Os corantes sintéticos apresentam uma função importante no ramo alimentício. Apesar de não agregarem valor nutritivo aos alimentos eles influenciam diretamente na aceitação do produto pelos consumidores (Huang et al., 2002). O grande problema é que a presença de baixas concentrações de corantes em efluentes (menor do que 1ppm) é altamente visível e indesejável (Nigam et al., 2000). O despejo de efluentes que passaram por processos de remoção de poluentes, mas que ainda possuem corantes dissolvidos, causam inibição da penetração da luz nos corpos hídricos prejudicando o processo de fotossíntese e conseqüentemente provocam alterações na biota aquática (Arami et al., 2005). Além disso, uma das características dos corantes comerciais é de que estes são desenvolvidos para resistir à fotodegradação natural que poderia ocorrer pela incidência da radiação solar (Forgacs et al., 2004).

Muitas indústrias alimentícias empregam processos de tratamento físico e biológico convencional para fazer a remoção de poluentes orgânicos e também sintéticos, mas conforme estudos divulgados na literatura estes processos físico-químicos e biológicos não são efetivos para remover poluentes recalcitrantes, como é o caso dos corantes sintéticos (Andreozzi et al., 1999).

Nesse contexto, novos e alternativos métodos químicos de remoção como os processos oxidativos avançados são considerados mais apropriados para tratar efluentes que contêm corantes orgânicos (Peternel et al., 2006) pois os agentes oxidantes como ozônio, $\mathrm{H}_{2} \mathrm{O}_{2}$, luz UV e a combinação destes com outros catalizadores possuem alta propriedade oxidativa e agem quebrando o grupo funcional responsável pela cor dos corantes (Fahmi et al., 2011).

O processo de oxidação fotocatalítica heterogênea utiliza semicondutores para promover a mineralização total de grande parte dos poluentes orgânicos, incluindo corantes (Kansal et al., 2007; Liu et al., 2006; Tariq et al., 2008).

Por este processo tem-se um aumento considerável de radical hidroxila que é gerado na superfície de um semicondutor (Gogate e Pandit, 2004). Os semicondutores mais utilizados são do tipo calcogênico como os óxidos $\mathrm{TiO}_{2}, \mathrm{ZnO}, \mathrm{ZrO}_{2}, \mathrm{CeO}_{2}$ etc, ou sulfurosos como $\mathrm{CdS}, \mathrm{ZnS}$, etc (Vazquez, 2002).

O objetivo deste trabalho é o estudo da degradação do azocorante vermelho Ponceau 4R, presente em uma solução sintética, utilizando foto-oxidação catalítica.

\section{MATERIAL E MÉTODOS}

\subsection{Padrão e Reagentes}

A amostra do corante alimentício Ponceau 4R, Food Red-7, $\mathrm{C}_{20} \mathrm{H}_{11} \mathrm{~N}_{2} \mathrm{O}_{10} \mathrm{~S}_{3} \mathrm{Na}_{3}$, com massa molecular de $604,46 \mathrm{~g} \mathrm{~mol}^{-1}$, utilizado no estudo foi doado pela empresa Saporiti do Brasil com referência do produto 2611-82-7. Os demais reagentes utilizados nos experimentos são de grau analítico sem nenhum tratamento prévio.

Para os experimentos a solução sintética foi preparada na concentração de $60 \mathrm{mg} \mathrm{L}^{-1}$ de corante 
Ponceau 4R em água destilada. Adotou-se esta concentração de corante em função de resultados de estudos anteriores, desenvolvidos por Lucas e Peres (2006), que demonstraram que alta concentração inicial de corante afeta a eficiência da reação, além de interferir na penetração de fótons, quando são utilizados processos com incidência de radiação ultravioleta.

\subsection{Curva padrão}

A quantificação da concentração das alíquotas de solução contendo corante antes e após o processo fotocatalítico foi realizada por meio da sua absorbância obtida por um espectrofotômetro Shimadzu, modelo 2410 PC.

Inicialmente foi realizada uma varredura no comprimento de onda, a fim de se determinar qual a absorção de luz máxima para o corante Ponceau 4R em solução aquosa. Em seguida foi construída a curva de calibração neste comprimento de onda.

Na construção da curva padrão do corante Ponceau 4R partiu-se de uma solução inicial de $0,025 \mathrm{~g}$ de corante em $1 \mathrm{~L}$ de água destilada. A partir desta solução-mãe foram preparadas as seguintes concentrações: $0,025 \mathrm{mg} \mathrm{mL}^{-1} ; 0,02 \mathrm{mg} \mathrm{mL}^{-1} ; 0,015 \mathrm{mg} \mathrm{mL}^{-1} ; 0,01 \mathrm{mg} \mathrm{mL}^{-1}$ e $0,005 \mathrm{mg}$ $\mathrm{mL}^{-1}$. Cada solução preparada foi lida em triplicata no espectrofotômetro.

\subsection{Ensaios experimentais}

O sistema reacional, conforme mostra a Figura 1, consistiu de um reator de vidro com capacidade de $250 \mathrm{~mL}$, com sistema de camisa de água para manter a solução em temperatura ambiente durante os ensaios e com agitação magnética para manter o semicondutor $\mathrm{TiO}_{2} \mathrm{em}$ suspensão na solução. A radiação ultravioleta foi fornecida por uma lâmpada de vapor de mercúrio de $125 \mathrm{~W}$ (sem o bulbo protetor), inserida na solução por meio de um bulbo de quartzo e fixada no centro do reator. Todo este aparato estava montado dentro de uma câmara para evitar dissipação de radiação. Em todos os experimentos foi utilizado volume reacional de $200 \mathrm{~mL}$, e os valores de $\mathrm{pH}$ e a quantidade de semicondutor $\left(\mathrm{TiO}_{2}\right)$ foram otimizados para a realização dos ensaios de fotocatálise, sendo que o pH igual a 4,0 e a concentração de $50 \mathrm{mg}$ de fotocatalisador em $200 \mathrm{~mL}$ de solução foram os valores que apresentaram o maior percentual de descoloração da solução contendo o corante. $\mathrm{O}$ pH das soluções de corante foi ajustado utilizando ácido clorídrico e hidróxido de sódio. Os experimentos foram conduzidos à temperatura ambiente.

As alíquotas foram retiradas em intervalos de tempo pré-determinados, totalizando 120 minutos de reação. 


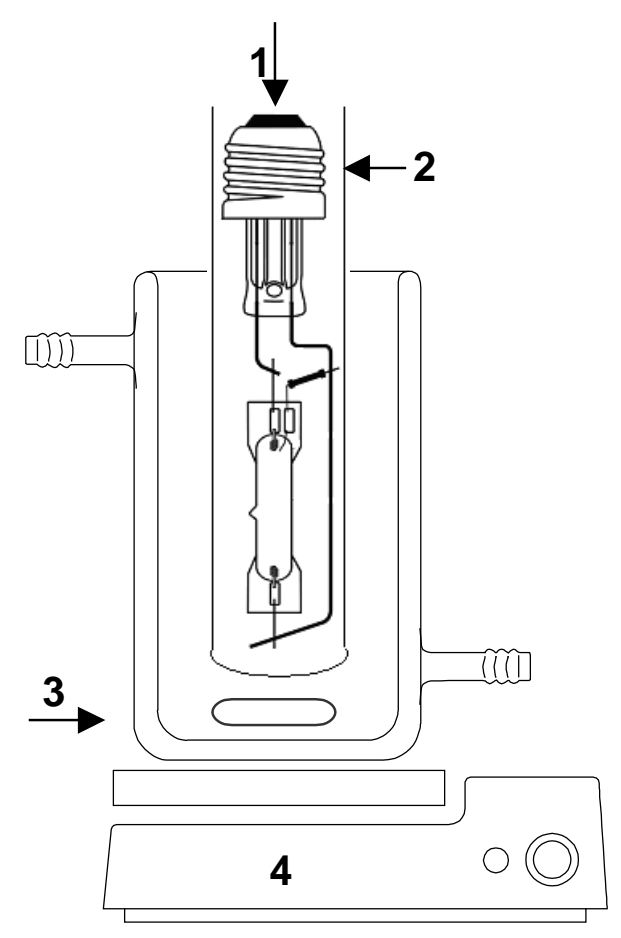

Figura 1 - Diagrama esquemático do fotoreator: lâmpada UV 125 W (1), bulbo protetor (2), reator encamisado e barra magnética (3) e agitador magnético (4).

\subsection{Determinação da concentração de Carbono Orgânico Total (COT)}

A determinação de carbono orgânico total foi realizada em um analisador de carbono orgânico total Shimadzu TOC-VCPH, com leitura em triplicata das amostras.

Esta análise determina o Carbono Total (CT) e o Carbono Inorgânico Total (CIT). O COT é a diferença entre o CT e CIT das amostras. Esta determinação indica o grau de mineralização dos compostos presentes em uma solução. Esta técnica fundamenta-se na oxidação catalítica de compostos orgânicos a elevadas temperaturas (tubo de combustão a $680{ }^{\circ} \mathrm{C}$ contendo platina suportada em alumina) e na determinação de $\mathrm{CO}_{2}$ por espectroscopia no infravermelho.

\section{RESULTADOS E DISCUSSÃO}

\subsection{Obtenção do comprimento de onda de máxima absorção do corante}

A varredura do comprimento de onda do azocorante vermelho Ponceau $4 \mathrm{R}$ é apresentada na Figura 2a. Observa-se que a máxima absorção de luz, na região do visível, para este corante é de 508 
nm. Com base neste dado fez-se a medição da absorbância das alíquotas amostradas utilizando este comprimento de onda para determinar a concentração residual de corante durante o tratamento. A curva padrão obtida para corante Ponceau 4R está apresentada na Figura 2b.

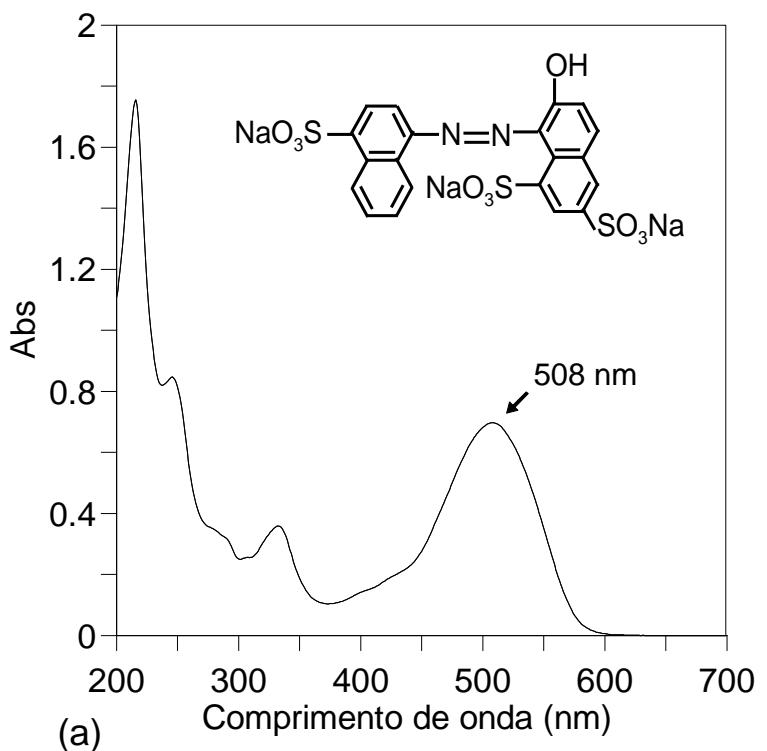

(a)

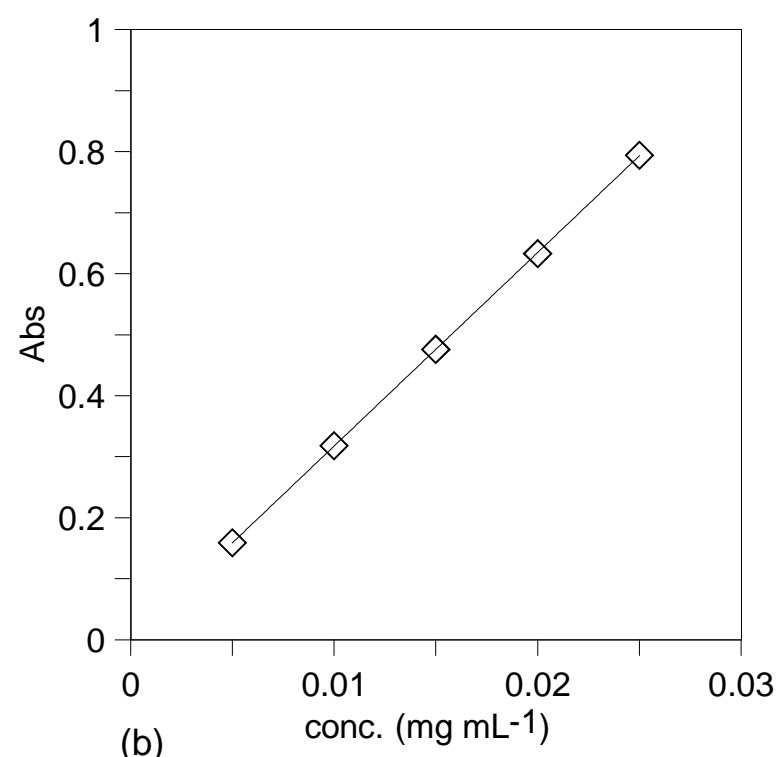

(b)

Figura 2 - (a) Varredura de absorção espectral do corante vermelho Ponceau 4R;

(b) curva padrão do corante vermelho Ponceau $4 \mathrm{R}$

\subsection{Degradação do corante}

A descoloração do Ponceau 4R em função do tempo de tratamento por processo fotocatalítico é mostrado na Figura 3. Verifica-se que a absorbância normalizada do corante $\mathrm{A} / \mathrm{A}_{0}$ decresce rapidamente nos primeiros minutos de tratamento.

Tal eficiência do processo também é atribuída a acidez do meio aquoso, com o uso de $\mathrm{pH} 4$, pois este favorece a adsorção do corante na superfície do semicondutor e consequentemente sua degradação. O percentual de degradação do cromóforo azo obtido no tempo de tratamento de 40 minutos foi de $99,40 \%$.

A capacidade de mineralização do corante pelo processo fotocatalítico foi investigada, pela determinação de carbono orgânico total (COT), obtendo-se os resultados apresentados na Figura 4. Os resultados indicam que, o processo em estudo apresentou uma eficiência de mineralização de $98,04 \%$, aos 120 minutos de tratamento. 


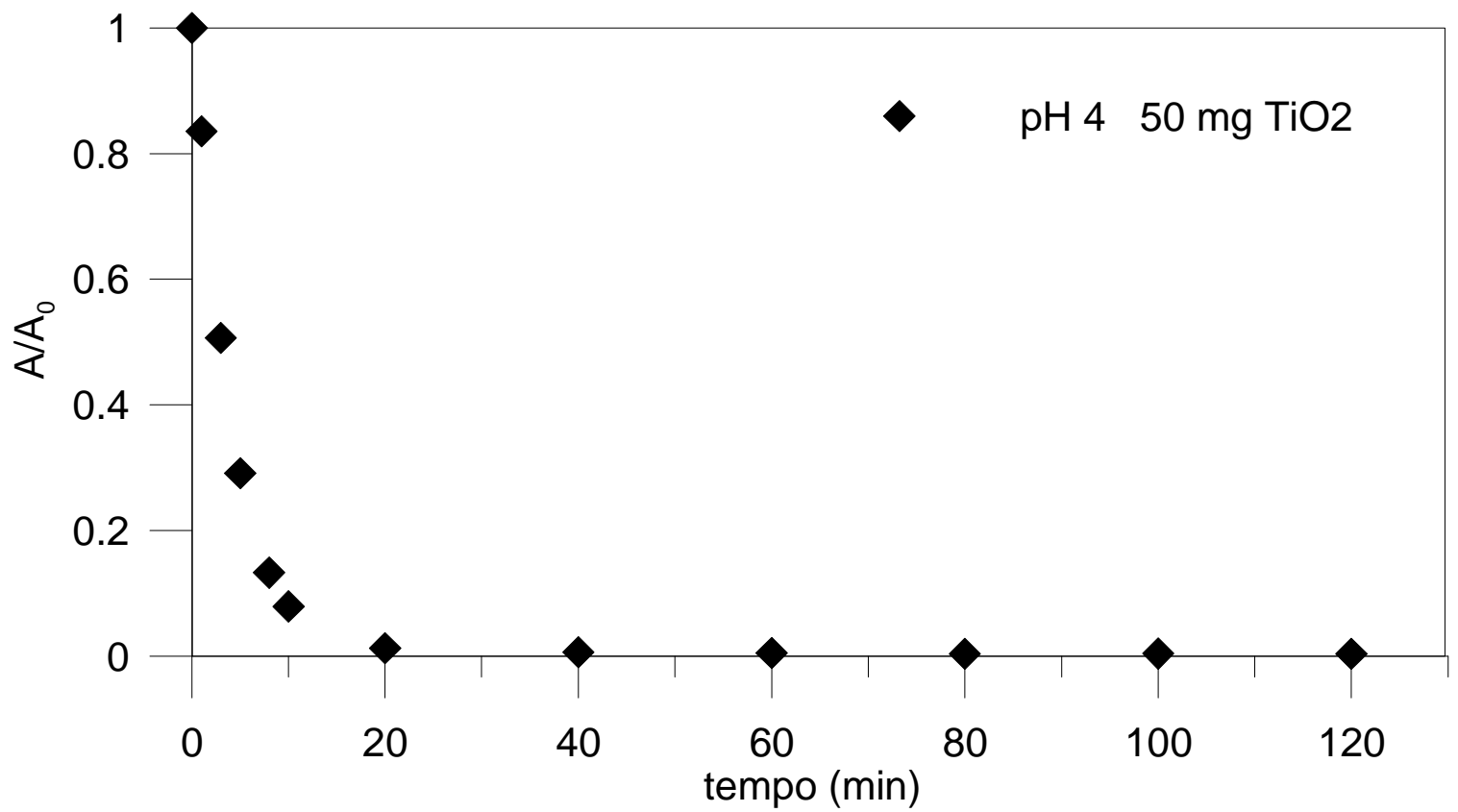

Figura 3 - Descoloração do corante Ponceau 4R $\left(\mathrm{C}_{0}=60 \mathrm{mg} \mathrm{L}^{-1}\right)$, pH 4,0, $50 \mathrm{mg}$ de $\mathrm{TiO}_{2}, 120$ minutos de reação, irradiação de $125 \mathrm{~W}$

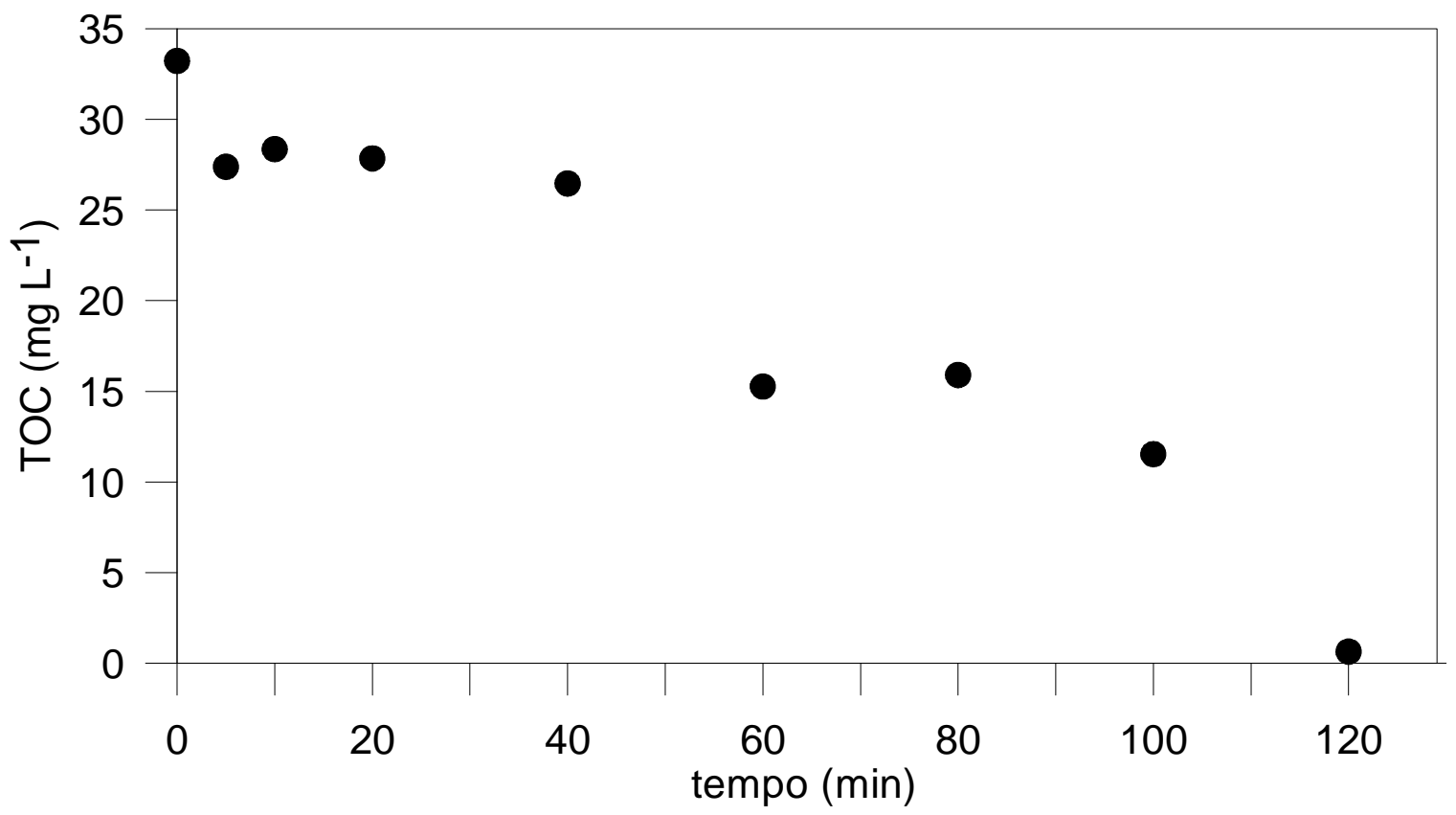

Figura 4 - Redução do COT para a solução de corante Ponceau 4R $\left(\mathrm{C}_{0}=60 \mathrm{mg} \mathrm{L}^{-1}\right)$, pH 4,0, $50 \mathrm{mg}$ de $\mathrm{TiO}_{2}, 120$ minutos de reação, irradiação de $125 \mathrm{~W}$ 


\section{9 a 22 de outubro de 2014 \\ Florianópolis/SC}

\section{CONCLUSÃO}

Os resultados obtidos neste estudo indicaram que o processo fotocatalítico é eficiente na descoloração de solução sintética contendo o corante azo Ponceau 4R com 40 minutos de reação, utilizando as seguintes condições experimentais: solução de corante Ponceau $4 \mathrm{R}\left(\mathrm{C}_{0}=60 \mathrm{mg} \mathrm{L}{ }^{-1}\right)$, $\mathrm{pH}$ 4,0, $50 \mathrm{mg}$ de $\mathrm{TiO}_{2}, 120$ minutos de reação e irradiação de $125 \mathrm{~W}$. A mineralização do corante somente é conseguida aos 120 minutos de tratamento, atingindo a remoção de $98,04 \%$ do carbono presente inicialmente na molécula de corante.

\section{REFERÊNCIAS}

ANDREOZZI, R.; CAPRIO, V.; INSOLA, A.; MAROTTA, R. Advanced oxidation processes (AOP) for water purification and recovery. Catal Today., v. 53, p. 51-59, 1999.

ARAMI, M; LIMAEE, N. Y.; MAHMOODI, N. M.; TABRIZI, N. S. Removal of dyes from colored textile wastewater by orange peel adsorbent: Equilibrium and kinetic studies. J Colloid Interf Sc. v. 288, p. 371-376, 2005.

BAUMGARTEN, M. G. Z. A eutrofização das águas de uma enseada do estuário da Lagoa dos Patos (RS) protegida pela legislação ambiental. Fepam em Revista. v. 3, p. 34-42, 2010.

FAHMI, M. R.; ABIDIN, C. Z. A.; RAHMAT, N. R. Characteristic of Colour and COD Removal of Azo Dye by Advanced Oxidation Process and Biological Treatment. Int Conf Biotech Environ Manage IPCBEE. Singapura. v. 18, p. 13-18, 2011.

FORGACS, E.; CSERHATI, T.; OROS, G. Removal of synthetic dyes from wastewaters: a review. Environ Int., v. 30, p. 953-971, 2004.

GOGATE, P. R.; PANDIT, A. B. A review of imperative technologies for wastewater treatment I: oxidation technologies at ambient conditions. Adv Environ Res., v. 8, p. 501-551, 2004.

HUANG, H. Y.; SHIH, Y. C.; CHEN, Y. C. Determining eight colorants in milk beverages by capillary electrophoresis. J Chromatogr A., v. 959, p. 317-325, 2002.

KANSAL, S. K.; SINGH, M.; SUD, D. Studies on photodegradation of two commercial dyes in aqueous phase using different photocatalysts. J Hazard Mater., v. 141, p. 581-590, 2007.

LIU, C. C.; HSIEH, Y. H.; LAI, P. F.; LI, C. H.; KAO, C. L. Photodegradation treatmente of azo dye wastewater by UV-TiO 2 process. Dyes Pigments., v. 68, p. 191-195, 2006.

LUCAS, M. S.; PERES, J. A. Decolorization of the azo dye Reactive Black 5 by Fenton and photoFenton oxidation. Dyes Pigments., v. 71, p. 236-244, 2006. 
NIGAM, P.; ARMOUR, G.; BANAT, I. M.; SINGH, D.; MARCHANT, R. Physical removal of textile dyes from effluents and solid-state fermentation of dye-adsorbed agricultural residues. Bioresource Technol., v. 72, p. 219-226, 2000.

PETERNEL, I.; KOPRIVANAC, N. KUSIC, H. UV-based processes for reactive azo dye mineralization. Water Res., v. 40, p. 525-532, 2006.

RAMJEAWON, T. Cleaner production in Mauritania cane-sugar factories. J Clean Prod., v. 8, p. 503-510, 2000.

TARIQ, M. A.; FAISAL, M.; SAQUIB, M.; MUNEER, M. Heterogeneous photocatalytic degradation of an anthraquinone and a triphenylmethane dye derivative in aqueous suspensions of semiconductor. Dyes Pigments., v. 76, p. 358-364, 2008.

VAZQUEZ, J. C. Evaluación analítica y optimización de procesos de oxidación avanzada en planta piloto solar. Tesis Doctoral, Departamento de Hidrogeologia Y Química Analítica, Universidade de Almería, 2002. 